\title{
Role of intestinal transit in the pathogenesis of gallbladder stones
}

\author{
R HERMON DOWLING MD FRCP, MARTIN J VEYSEY MB MRCP, STEPHEN P PEREIRA BSc MB MRCP, \\ S HYDER HUSSAINI MD MRCP, LINZI A THOMAS MB MRCP, JOHN AH WASS MD FRCP, GERARD M MURPHY PhD FRSC
}

RH Dowling, MJ Veysey, SP Pereira, SH Hussaini, LA THOMAS, JAH WASS, GM MURPHY. Role of intestinal transit in the pathogenesis of gallbladder stones. Can J Gastroenterol 1997;11(1):57-64. Increasing evidence implicates prolonged intestinal transit (slow transit constipation) in the pathogenesis of conventional gallbladder stones (GBS), and that of gallstones induced by long term octreotide (OT) treatment. Both groups of GBS patients have multiple abnormalities in the lipid composition and physical chemistry of their gallbladder bile - associated with, and possibly due to, an increased proportion of deoxycholic acid (DCA) (percentage of total bile acids). In turn, this increase in the percentage of DCA seems to be a consequence of prolonged colonic transit. Thus, in acromegalic patients OT treatment significantly prolongs large bowel transit time (LBTT) and leads to an associated increase of the percentage of DCA in fasting serum (and, by implication, in gallbladder bile). LBTT is linearly related to the percentage of DCA in fasting serum and correlates significantly with DCA input (into the enterohepatic circulation) and DCA pool size. However, these adverse effects of OT can be overcome by the concomitant use of the prokinetic drug cisapride, which normalizes LBTT and prevents the rise in the percentage of serum DCA. Therefore, in OT-treated patients and other groups at high risk of developing stones, it may be possible to prevent GBS formation with the use of intestinal prokinetic drugs.

Key Words: Bile acid-metabolizing bacterial enzymes, Biliary cholesterol saturation, Cholesterol gallstones, Deoxycholic acid, Intestinal prokinetic drugs, Intestinal transit

\section{Rôle du transit intestinal dans la pathogenèse des calculs biliaires}

RÉSUMÉ : Les preuves s'accumulent et impliquent de plus en plus le ralentissement du transit intestinal dans la pathogenèse des calculs biliaires classiques et dans celle des calculs provoqués par un traitement aux octréotides (OT) prolongé. Les deux groupes de patients porteurs de tels calculs présentent de nombreuses anomalies sur la plan de la composition des lipides et des propriétés physico-chimiques de leur bile, qui se trouvent associées et peut-être aussi dues à une augmentation de la proportion d'acide désoxycholique (ADC) (pourcentage des acides biliaires totaux). En retour, cette augmentation du pourcentage d'ADC semble être une conséquence du ralentissement du transit au niveau du côlon. Ainsi, chez les patients qui souffrent d'acromégalie, le traitement par octréotides prolonge significativement le temps de transit au niveau du côlon et entraîne une augmentation associée du pourcentage d'ADC dans le sérum à jeun (et par conséquent dans la bile). Le transit au niveau du côlon est en lien linéaire avec le pourcentage d'ADC dans le sérum à jeun et est en corrélation significative avec l'excrétion d'ADC (dans la circulation entéro-hépatique) et avec le volume du capital d'ADC. Toutefois, ces effets indésirables des OT peuvent être surmontés au moyen d'un traitement concomitant avec le procinétique cisapride qui normalise le temps de transit intestinal et empêche l'élévation des taux sériques d'ADC. Par conséquent, chez les patients traités par octréotides et autres groupes à haut risque pour ce qui est calculs, il est possible de prévenir la formation des calculs biliaires en administrant des procinétiques.

Gastroenterology Unit, Guy's Hospital Eु Campus, UMDS of Guy's Eु St Thomas' Hospital, London, United Kingdom; Department of Endocrinology, John Radcliffe Hospital and Oxford University, Oxford, United Kingdom

Correspondence and reprints: Professor RH Dowling, Gastroenterology Unit, 18th floor, Guy's Hospital, London, United Kingdom SE1 9RT. Telephone 44-171-955-4564, fax 44-171-955-4230

Received for publication July 20, 1996. Accepted August 1, 1996 
$\mathrm{O}$ ver the past 10 years the concept of a triple defect in the pathogenesis of cholesterol-rich gallbladder stones has become accepted (1). This triple defect - supersaturated gallbladder bile; a nucleation defect with an imbalance between promoters and inhibitors of cholesterol microcrystal precipitation; and gallbladder motor dysfunction with impaired, meal-stimulated gallbladder emptying - is often depicted as a Venn diagram, with overlapping circles to emphasize the belief that the three abnormalities must co-exist before stones can form. Recently, however, modifications to the Venn diagram have been proposed (2), with five or even six overlapping circles to incorporate 'new' concepts, such as the role of mucus glycoprotein (MGP) synthesis and secretion by the gallbladder. MGP contributes to gallstone formation not only by promoting nucleation (3-5) but also by trapping the cholesterol microcrystals in a surface mucus gel on the gallbladder mucosa (6).

The idea that abnormal intestinal motility may also contribute to gallstone formation is not new, although the suggestion that gallstone disease could be secondary to changes in intestinal transit is far from widely accepted. The purpose of this contribution, therefore, is to review the evidence, both direct and indirect, that changes in intestinal transit may predispose to lithogenic changes in biliary bile acid and bile lipid composition, and to cholesterol gallbladder stone formation.

For many years the main protagonists of the intestinal transit theory were the Bristol group (7) and a team from the Netherlands (8), although studies from the United States $(9,10)$ and Sweden $(11)$ also showed a relationship between intestinal transit and bile composition. A consensus from these studies is that prolongation of intestinal transit increases either the anaerobic bacterial enzymatic biotransformation (deconjugation followed by 7-alpha dehydroxylation) of conjugated cholic acid to deoxycholic acid (DCA) and/or the absorption of this secondary bile acid. Whatever the mechanism, the net effect is an increase in the percentage of DCA conjugates in bile (expressed as a percentage of the total bile acids), and this favours biliary cholesterol hypersecretion, increases in biliary cholesterol saturation and gallstone formation. Recently other investigators have extended these observations in experimental animals (12-14) and humans $(15,16)$.

In their comprehensive review, Marcus and Heaton (7) noted that the mean percentage of DCA in duodenal bile was higher in gallstone carriers than in controls in 19 of 20 comparisons. Furthermore, in eight of the 20 studies the differences were statistically significant. Several other groups have confirmed their findings (15-17).

These observations lack the power of a meta-analysis. However, they strongly support the conclusion that, with few exceptions, the mean percentage of DCA in bile is greater in gallstone carriers than in controls, even if the range of mean values for the percentage of DCA in the bile of controls varies enormously from study to study, and often overlaps that found in gallstone subjects. Furthermore, this increase in the relative proportion of DCA conjugates in bile or in the absolute size of the DCA pool (at present it is unknown which of these two is most important) occurs even though the total bile acid pool size in gallstone patients is often less than normal (18-20).

\section{ROLE OF INTESTINAL TRANSIT IN THE PATHOGENESIS OF OCTREOTIDE-INDUCED GALLBLADDER STONES}

Octreotide (OT) is a long-acting somatostatin analogue that is an effective treatment for acromegaly. However, it induces gallbladder stone formation in $13 \%$ to $60 \%$ of patients treated for three to 51 months (21-24). Most, but not all, of these OT-associated stones are cholesterol-rich (25). OT acts by suppressing circulating levels of growth hormone and insulin-like growth factor-I, but its effects on peptide hormone secretion are nonspecific. It also inhibits mealstimulated cholecystokinin (CCK) release from the intestine (26-29) and, largely as a result, suppresses gallbladder contraction in response to food $(27,29)$. Indeed, we (30) have confirmed that both acute and chronic OT treatment effectively abolishes meal-stimulated gallbladder emptying.

Until recently, suppression of CCK release and gallbladder contraction was considered to be the principal, if not the sole, mechanism for the induction of OT-induced gallbladder stones. However, given the multiplicity of factors involved in the development of 'conventional' gallstones, unrelated to acromegaly or OT treatment, it is important also to study bile acid and lipid composition and the physical chemistry of gallbladder bile. Since this must be done in fresh bile, the technique of ultrasound-guided, percutaneous, transhepatic, fine needle puncture of the gallbladder was used to aspirate samples from patients with conventional gallbladder stones (disease controls); acromegalic patients with OT-associated gallbladder stones; and stone-free acromegalic patients untreated with OT $(31,32)$. (In retrospect, results in these patients were comparable with those in historical control subjects.)

Results of these studies have been published in full elsewhere (16). In brief, gallbladder bile from the acromegalic patients showed changes comparable with those seen in patients with conventional cholesterol-rich gallbladder stones, and was different in composition from that seen in stone-free 'controls'. Thus, on average, gallbladder bile from patients with OT-associated gallbladder stones was supersaturated with cholesterol, had a high percentage of the total biliary cholesterol in the vesicular fraction and a high molar ratio of cholesterol:phospholipids in the vesicles (an index of vesicular instability). Patients with OT-associated gallbladder stones also had pathologically rapid nucleation of cholesterol microcrystals. These changes were associated with an increase in the mean percentage of DCA conjugates in bile, which was twice as high in both groups of stone carriers as that in the stone-free controls.

The abnormal bile composition seems to be due to OT treatment rather than to the presence of stones. Thus, when paired studies were carried out in a small number of acromegalic patients, before and during OT treatment (16), the percentage of DCA in bile doubled and the cholesterol satu- 
ration index (CSI) rose significantly, even in the absence of gallbladder stone formation.

\section{MECHANISM FOR OT-INDUCED INCREASE IN THE PERCENTAGE OF DCA IN BILE}

The mechanism whereby OT treatment increases the percentage of DCA conjugates in bile is not fully understood and is under investigation. However, strong circumstantial evidence suggests that it is secondary to OT-induced changes in intestinal transit. Results of earlier studies $(26,33-36)$ showed that a single injection of OT significantly prolonged small bowel transit in controls. However, there was little previous information about the effects of chronic OT treatment on both small and large bowel transit in acromegalic patients.

To study the effects of chronic OT treatment on bowel transit in acromegalic patients, we (30) measured the mouth-to-cecum transit time (MCTT) using the breath hydrogen technique $(37,38)$ in control subjects and acromegalic patients given a subcutaneous injection of either saline (placebo) or $50 \mu \mathrm{g}$ OT, 30 mins before a fat-rich liquid test meal (Ensure; Abbott Laboratories) $(250 \mathrm{~mL})$ plus $20 \mathrm{~mL}$ lactulose as a substrate for hydrogen. MCTT was measured after a single injection of OT (acute studies) or during long term OT treatment of the acromegalic patients (chronic studies). We (30) also used a radio-opaque marker shape technique (39) to study whole gut and large bowel transit times (LBTTs) in the same groups of individuals, that is, control subjects, acromegalic patients untreated with OT and acromegalics on long term OT therapy. Studies of large bowel transit are particularly relevant because the cecum and colon are thought to be the principal sites for the conversion of cholic acid to DCA (40-42).

Our results confirmed that a single $50 \mu \mathrm{g}$ injection of OT markedly prolonged the MCTT in control subjects (30). We also showed that small bowel transit (MCTT) in acromegalic patients was significantly longer than that in controls. Despite this, OT further prolonged the MCTT in acromegalic patients - often to more than $5 \mathrm{~h}$, by which time the test was abandoned if there had been no rise in breath hydrogen excretion (Figure 1).

Acromegalic patients again had significantly longer large bowel transit times than control subjects but, in unpaired studies, there was no further prolongation of LBTT in patients receiving long term OT (Figure 2). This observation supports the results of a recent study by von der Ohe et al (43) who showed that the effects of OT on intestinal motility were confined to the small bowel and largely spared the colon. However, these researchers studied manometry in the cleansed colon of control subjects, while we (30) measured intestinal transit in the unprepared bowel of both normal individuals and acromegalic patients. Therefore, the two studies are not directly comparable, even if a recent report from France (44) suggests that pressure recordings are comparable in the cleansed and noncleansed colon.

We (45) recently extended our observations by performing paired, before and during treatment, studies of large

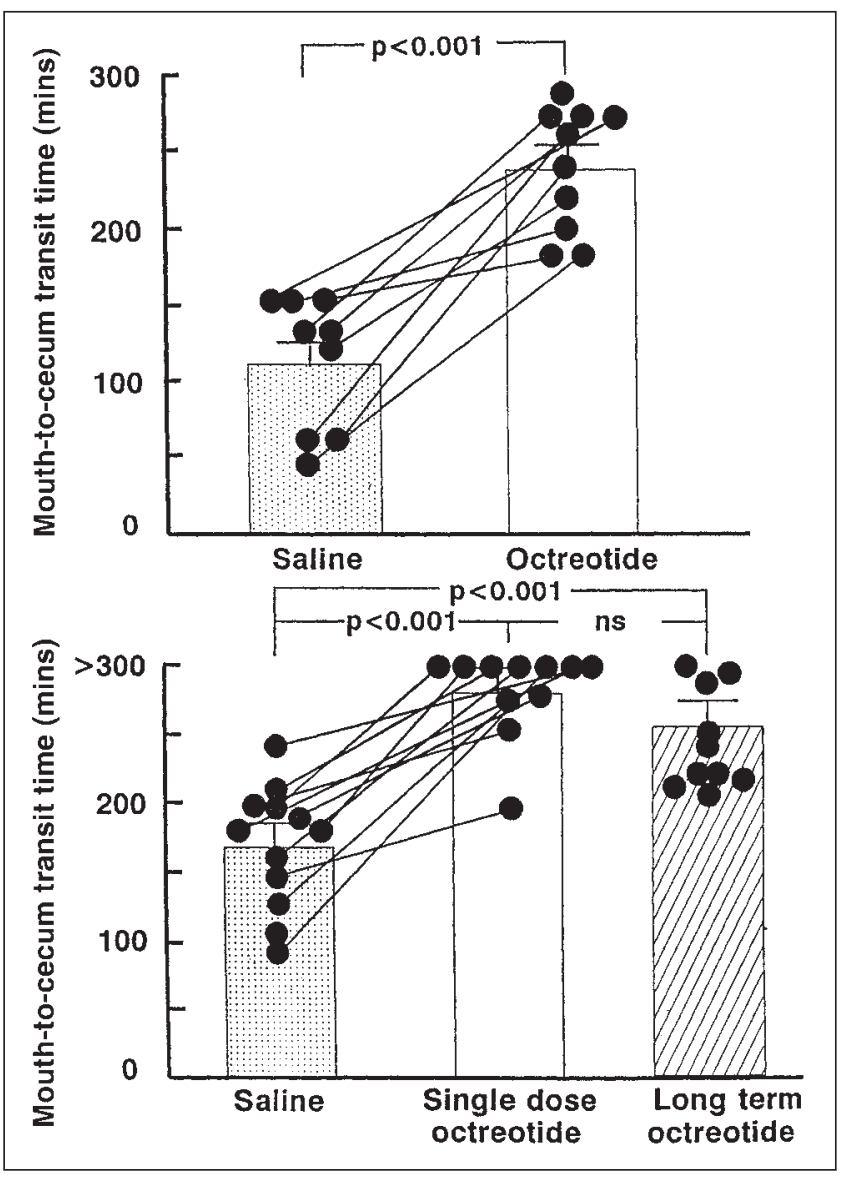

Figure 1) Mouth-to-cecum transit time, measured by the breath hydrogen technique, in control subjects (upper panel) and acromegalic patients (lower panel) given a subcutaneous injection of either saline or octreotide $(50 \mu g) 30$ mins before a fat-rich, lactulose-containing liquid meal. Data for acromegalic patients during long term octreotide treatment are also given. Reproduced with permission from reference 30

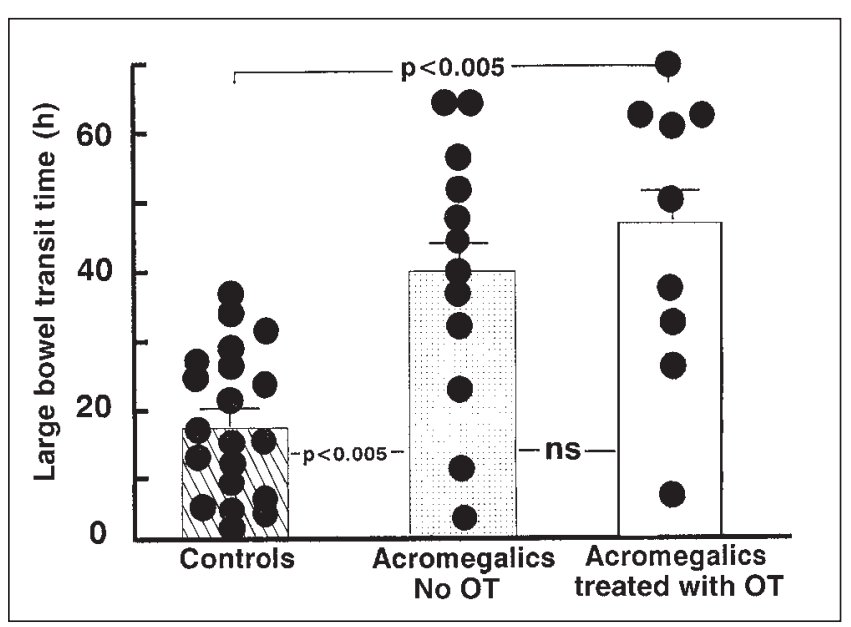

Figure 2) Large bowel transit time in control subjects, acromegalic patients untreated with octreotide (OT) and acromegalic patients treated long term with OT. ns Not significant. Reproduced with permission from reference 30

bowel transit in acromegalic patients on long term OT; we found that the somatostatin analogue consistently and significantly increased the LBTT. 
TABLE 1

Selected summary of results from reference 15 suggesting that there is an inter-relationship between the percentage of deoxycholic acid and the saturation of gallbladder bile, which, in turn, is related to changes in gallbladder emptying and small bowel transit in gallstone patients compared with controls

\begin{tabular}{llcl}
\hline & \multicolumn{3}{c}{ Gallbladder } \\
& Controls & stone patients & $\mathbf{P}$ \\
\hline Deoxycholic acid (\%) & $10.2 \pm 0.9$ & $21.7 \pm 1.4$ & $<0.001$ \\
Cholesterol saturation index & $0.96 \pm 0.03$ & $1.63 \pm 0.08$ & $<0.0001$ \\
Gallbladder emptying (\%) & $78.4 \pm 4$ & $58 \pm 3$ & $<0.0005$ \\
Small bowel transit (mins) & $126 \pm 9$ & $198 \pm 9$ & $<0.01$ \\
\hline
\end{tabular}

\section{RELATIONSHIP BETWEEN LBTT AND THE PERCENTAGE OF DCA IN BILE AND SERUM}

If $O T$-induced changes in large bowel transit are responsible for the increase in the percentage of DCA in bile, one might expect to find a significant correlation between these two variables. This has not been studied directly, although the report by Marcus and Heaton (46) comes close. These authors did not study the effects of OT on intestinal transit but did show that there were statistically significant correlations between the change in whole gut transit time (induced in constipated subjects by taking standardized senna or in normal volunteers by taking loperamide) and, first, the change in DCA pool size and, second, the change in the percentage of DCA in duodenal bile.

We (47) have yet to show that there is a relationship between OT-induced changes in intestinal transit and the percentage of DCA in bile, but we have studied this indirectly by relating LBTT to fasting serum DCA levels in controls and acromegalic patients. For both conjugated and unconjugated bile acids, we found highly significant linear relationships between the percentage of DCA in the serum and LBTT. The interpretation of this finding is based on the assumption that measurement of serum bile acids provides an accessible 'window' for studying biliary bile acids indirectly. It also assumes that, ultimately, there is a dynamic exchange between the bile acid pools in the serum and in bile. (After food ingestion, there may be a temporary disequilibrium between the bile acid pool in the serum and that in bile as a result of selective shunting of unconjugated [and, to a lesser extent, glycine conjugated] bile acids into the peripheral circulation, and a preferential transfer of the conjugates which have a high first-pass hepatic clearance rate - through the liver and into the bile.) Indeed, this is the justification for using stable isotopes to measure bile acid pool size and turnover rate by the Stellaard technique (48) in the peripheral circulation, a method that we are using to measure cholic and DCA kinetics in acromegalic patients before and during long term OT treatment.

To date, we have published only preliminary results of DCA pool size and input (into the enterohepatic circulation) rate in controls and patients with slow transit constipa- tion (49). We found that the mean DCA pool size and input rate were both significantly greater in the constipated individuals than in the controls and, once again, there were significant linear relationships between LBTT and both the DCA pool size and input rate.

\section{ROLE OF INTESTINAL TRANSIT IN THE PATHOGENESIS OF 'CONVENTIONAL' CHOLESTEROL GALLSTONE DISEASE}

If prolongation in intestinal transit plays a major role in the development of OT-induced gallbladder stones, what is the evidence that this pathogenetic mechanism also applies to conventional gallstone disease? Once again, the bulk of the evidence on this subject comes from studies by the Bristol group. As noted above, Marcus and Heaton (46) showed that when constipation was induced by motility inhibiting drugs, the percentage of DCA and the cholesterol saturation of duodenal bile increased. Conversely, when rapid intestinal transit was induced with a variety of regimens (including lactulose, senna or a high fibre, bran-supplemented diet), the percentage of DCA and the cholesterol saturation fell $(7,46)$.

Furthermore, from ultrasound-based epidemiological studies of gallstone prevalence in western England, a subgroup of women with gallstones was identified who had no obvious risk factors for gallstone formation. In this population of normal weight women, whole gut transit time and fecal wet weight were measured and compared with results from age-matched controls. In the gallstone carriers, mean whole gut transit time was nearly $20 \mathrm{~h}$ longer than that in controls, while their stool output was almost half that seen in stone-free individuals. In other words, normal weight woman with gallstones seemed to suffer from slow transit constipation (50).

The Bristol findings are supported by the results of a recent Japanese/Swedish study by Shoda and co-workers (15). They also found that the cholesterol saturation and the percentage of DCA conjugates in bile were linked to changes in gallbladder and intestinal motility, both these variables being significantly different in patients versus controls ( $\mathrm{Ta}$ ble 1).

Finally, Xu et al (13) studied ground squirrels that were given a lithogenic ( $1 \%$ cholesterol) diet. These animals too developed supersaturated bile with rapid nucleation of cholesterol microcrystals and prolonged intestinal transit. They also showed that the abnormal small bowel transit could be corrected by treatment with the prokinetic agent erythromycin, which corrected the abnormalities in bile composition and physical chemistry (14).

\section{UNIFYING HYPOTHESIS TO EXPLAIN OT-INDUCED GALLBLADDER STONE FORMATION}

Based on the aforementioned results, we developed a hypothetical sequence of events to explain the pathogenesis of OT-induced gallbladder stones (summarized schematically in Figure 3). The hypothesis was proposed primarily to ex- 
plain the development of gallbladder stones in patients receiving long term OT treatment. However, as discussed below, it may also apply to the pathogenesis of cholesterol gallstones in general, which form spontaneously.

According to this hypothesis, treatment with the somatostatin analogue OT leads to a greater than normal formation of DCA in the intestine as a result of increased intestinal bacterial 7-alpha dehydroxylation of cholic acid. However, to increase the proportion of DCA conjugates in bile, the newly biotransformed DCA has to be absorbed from the intestine, taken up by the liver, conjugated with glycine or taurine, and secreted into bile.

We $(51)$ and others $(11,15,52-56)$ have shown that there is a significant linear relationship between the percentage of DCA and the CSI. An explanation for this observation may be that the hydrophobic DCA promotes hypersecretion of biliary cholesterol. Carulli et al (57) showed that acute enrichment of the bile acid pool with DCA, achieved by intraduodenal infusion of DCA in postcholecystectomy T tube patients, stimulated a high output of biliary cholesterol.

DCA-rich bile may influence gallbladder stone formation by mechanisms other than by its effect on biliary cholesterol secretion. Cantafora et al (58), van Berge Henegouwen et al (59) and Hatsushika et al (60) showed that there was a correlation between the percentage of DCA and the proportion of arachidonic acid-rich phospholipids in bile. In support of this, we (61) showed (again in paired, before and during treatment studies) that chronic OT therapy significantly increased not only the percentage of DCA and the CSI, but also the proportion of arachidonic acid-rich phosphatidylcholine, expressed as a percentage of total biliary lecithin, in gallbladder bile. This increase affected the 16:0-20:4 and 18:0-20:4 phosphatidyl cholines (that is, phosphatidyl cholines with 16 or 18 carbon atoms and no double bonds in the sn 1 position and 20 carbons with four double bonds in the sn2 position). We (62) also confirmed that there were significant linear relationships between the percentage of DCA and the proportion of arachidonic acid-rich phospholipids in gallbladder bile.

Whether this increase in arachidonic acid-rich phosphatidylcholine, or the associated increase in biliary cholesterol saturation, is responsible for an increase in the synthesis and secretion of MGP by the gallbladder mucosa, which is thought to occur in gallbladder stone disease, is debatable. Whatever the mechanism, we also found increased concentrations of biliary MGP in gallbladder bile from patients on long term OT treatment (although the difference between mean before and during treatment MGP results was not statistically significant) (62).

Further discussion of the controversial role of arachidonic acid-rich phospholipids in gallbladder bile, prostaglandin metabolism in the gallbladder wall, MGP synthesis and secretion by the gallbladder, and the possible relationship between prostaglandins and gallbladder motility, is beyond the scope of this review. In theory, prolongation of intestinal transit could lead to a complex series of events affecting the

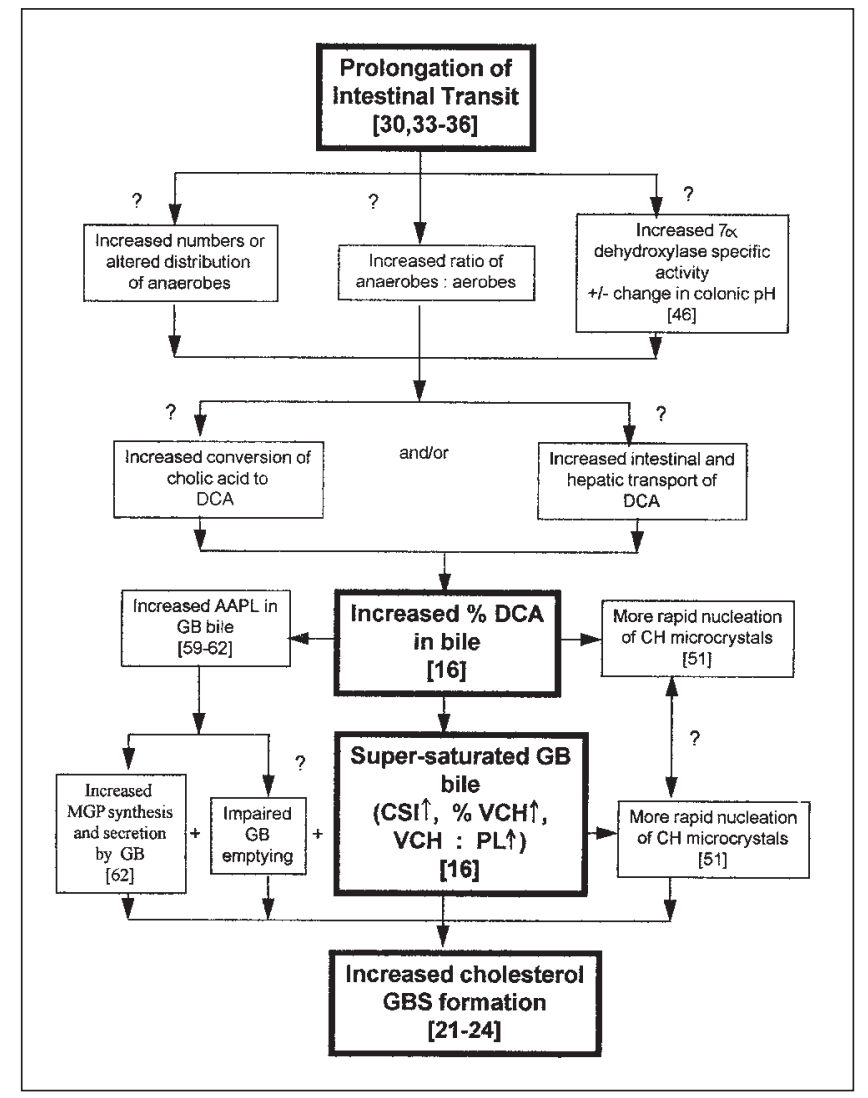

Figure 3) Hypothetical sequence of events to explain how prolongation of intestinal transit might predispose to a greater than normal incidence of cholesterol-rich gallbladder stones (GBS). This sequence was based on studies of octreotide-induced GBS but it may also apply to 'conventional' cholesterol gallstone disease (that occurring spontaneously and unrelated to octreotide treatment or acromegaly). The boxes in bold type represent proven facts while other boxes represent possible mechanisms or steps, which are currently undergoing active investigation. The flow diagram should NOT be interpreted as suggesting that intestinal transit is the sole, or even the principal, pathogenetic factor in the development of gallstones. Moreover, the flow diagram does not necessarily imply, for example, that prolongation of intestinal transit is more important than impaired gallbladder (GB) emptying in the pathogenesis of octreotide-associated stones. Numbers in square brackets are reference numbers. AAPL Arachidonic acid-rich phospholipids; CH Cholesterol; CSI Cholesterol saturation index; DCA Deoxycholic acid; MGP Mucus glycoprotein; VCH Total biliary $\mathrm{CH}$ in the vesicular fraction; VCH:PL Molar ratio of $\mathrm{CH}$ :phospholipids in the vesicular fraction (an index of vesicles stability/instability and the propensity of the vesicles to nucleate CH microcrystals). Modified and reproduced with permission from STA Custom Communications Inc

gallbladder's MGP production; impaired gallbladder emptying; lithogenic changes in bile acid and bile lipid composition; more rapid nucleation of cholesterol microcrystals; and cholesterol gallbladder stone formation (Figure 3). Although this hypothetical sequence of events is supported by reasonably strong direct and indirect evidence, it does not imply that altered intestinal transit is the sole, or even the prime, pathogenetic mechanism in the development of either OT-induced or 'conventional' cholesterol gallstones. The powerful effect of OT on gallbladder motility - both through inhibition of meal-stimulated CCK release from the 


\begin{tabular}{ll}
$\begin{array}{l}\text { TABLE } 2 \\
\text { List (incomplete) of possible prokinetic agents that might } \\
\text { have been used to stimulate gallbladder emptying, intes- } \\
\text { tinal transit or both }\end{array}$ \\
\hline $\begin{array}{l}\text { Agent } \\
\text { High fibre, } \\
\text { bran-supplemented diets }\end{array}$ & $\begin{array}{l}\text { Pomare et al, } 1976(73) \\
\text { Hood et al, 1993 (74) } \\
\text { Senna laxatives } \\
\text { Cholecystokinin } \\
\text { Cholestryamine }\end{array}$ \\
$\begin{array}{l}\text { Indomethacin } \\
\text { Cisapride }\end{array}$ & $\begin{array}{l}\text { Sitzmann et al, 1990 (65) } \\
\text { Portincasa et al, 1994 (75) }\end{array}$ \\
Orythromycin and analogues & Cannell et al, 1992 (76) \\
& $\begin{array}{l}\text { Carzio et al, 1986 (77) } \\
\text { Wiseman and Faulds, 1994 (78) }\end{array}$ \\
& $\begin{array}{l}\text { Weber et al, 1993 (80) } \\
\text { Xu et al, 1995 (14) }\end{array}$ \\
Lactulose & Thornton and Heaton, 1981 (81) \\
\hline
\end{tabular}

intestine and at an end-organ (gallbladder myocyte) level is undisputed.

There is no way of quantifying the relative contribution of these various pathogenetic factors to gallstone formation. Nonetheless, as in conventional gallbladder stone disease, multiple mechanisms are involved in the development of OT-induced gallbladder stones, and prolongation of intestinal transit must now be considered as a further defect, depicted by yet another circle in the Venn diagram of gallstone pathogenesis.

\section{CAN GALLSTONE FORMATION BE PREVENTED BY USING PROKINETIC AGENTS?}

The precedent that prokinetic drugs may prevent the development of gallstones comes from studies of patients at risk of sludge and stone formation during total parenteral nutrition (63) or in intensive care (64). Sitzmann and colleagues (65) showed that injections of CCK markedly inhibited sludge and stone formation in patients receiving total parenteral nutrition while Hasse et al (66) found that $1.5 \mu \mathrm{g}$ ceruletid (caerulin)/kg body weight reduced gallbladder sludge in $95 \%$ of patients in a surgical intensive care unit. CCK is prokinetic to the intestine as well as the gallbladder, but since CCK must be injected (or infused) we argued that it is unlikely to be acceptable as long term prophylaxis in patients at risk of gallstone formation during chronic OT treatment. Hasse and colleagues (66) came to the same conclusion; ceruletid treatment caused frequent and often severe side effects in $67.5 \%$ of their patients.

Table 2 lists candidate prokinetic regimens that might have been tried in an attempt to counter this iatrogenic disease. For complex reasons, however, we chose cisapride. Oral cisapride, $10 \mathrm{mg}$ four times/day, prevents prolongation of both MCTT and LBTT seen during OT treatment (67). Thus, LBTT increased from $39 \pm 4.9 \mathrm{~h}$ in acromegalic patients untreated with OT to $54 \pm 4.3 \mathrm{~h}$ in those taking long term OT, while patients given cisapride plus OT had LBTTs of $30 \pm 4.4 \mathrm{~h}$. There were corresponding changes in the percentage of DCA in fasting serum, which increased from $15 \pm 1.8 \%$ before OT to $24 \pm 2.9 \%$ in patients on long term OT plus placebo, but fell to $13 \pm 4.5 \%$ when cisapride ( $40 \mathrm{mg} /$ day for two weeks) was added to the long term OT. In fact, in this study (67) there was a significant linear relationship between LBTT and the percentage of DCA in serum $(r=0.76$; $\mathrm{P}<0.005$ ).

The observation that cisapride shortens LBTT is consistent with the results of most, but not all, previous studies which show that cisapride accelerates both small and large bowel transit. Thus, El Oufir and colleagues (68) titrated the amount of cisapride in control subjects "to approximately halve the spontaneous transit time". Patients were started on $20 \mathrm{mg} /$ day cisapride, which increased to $60 \mathrm{mg} /$ day "if the desired effect was not achieved". They showed that the mean transit time was significantly shortened from $73 \pm 11 \mathrm{~h}$ in the control period to $47 \pm 5 \mathrm{~h}$ after cisapride $(\mathrm{P}<0.05)$. This induced change in transit was associated with an increase in the concentrations of butyrate and propionate, and a decrease in the $\mathrm{pH}$ of the feces, which suggests that changes in intestinal transit can influence colonic/fecal $\mathrm{pH}$ by influencing short chain fatty acid production, absorption or both.

We have recently determined the optimum reaction conditions, in vitro, for measuring the two intestinal bacterial enzymes responsible for conversion of the conjugates of cholic acid to unconjugated DCA (69). This is part of an on-going program of research designed to examine the inter-relationship between the 'input' of DCA into the enterohepatic circulation (as judged by the percentage of DCA in fasting serum and gallbladder bile, and the DCA pool size, measured by a stable isotope dilution technique) and each of the following: intestinal transit; luminal $\mathrm{pH}$; quantitative bacterial flora; and bacterial enzyme activities (deconjugation and 7-alpha dehydroxylation) in the cecum/ right colon.

Returning to the finding that cisapride not only shortened LBTT, but also reduced serum (and, by implication, biliary) DCA levels to normal, we conclude that if changes in intestinal transit are rate-limiting in the pathogenesis of OT-induced gallbladder stones, cisapride should prevent their formation. Conversely, if OT inhibition of mealstimulated gallbladder emptying is more important than its effect on intestinal transit, cisapride may not be the answer. Thus, in common with others $(70,71)$, we (72) found that cisparide increased, rather than decreased, fasting gallbladder volume in both non-acromegalic patients and acromegalics taking long term OT. It also significantly increased the residual (postprandial) gallbladder volume in acromegalic patients on long term OT.

If we can confirm that cisapride not only reverses the effects of OT on small and large bowel transit, but also prevents the OT-induced increase in DCA pool size, the increase in the percentage of DCA in bile, and the associated increases in biliary cholesterol saturation and the speed of microcrystal nucleation, then we believe that a formal prospective study with cisapride is justified to learn whether we 
can prevent cholesterol gallstone formation in high risk groups, such as acromegalic patients taking long term OT treatment.

\section{REFERENCES}

1. Dowling RH, Gleeson D, Ruppin DC, Murphy GM and the British/Belgian Gallstone Study Group. Gallstone recurrence and post-dissolution management. In: Paumgartner G, Stiehl A, Gerok W, eds. Enterohepatic Circulation of Bile Acids and Sterol Metabolism. Lancaster: MTP Press Limited, 1985:361-9.

2. Carey MC. Formation of cholesterol gallstones: the new paradigms. In: Paumgartner G, Stiehl A, Gerok W, eds. Trends in Bile Acid Research. Dordrecht: Kluwer Academic Publishers, 1989:259-81.

3. Lee SP, LaMont JT, Carey MC. Role of gallbladder mucus hypersecretion in the evolution of cholesterol gallstones. Studies in the prairie dog. J Clin Invest 1981;67:1712-23.

4. Gallinger S, Taylor RD, Harvey PRC, Petrunka CN, Strasberg SM. Effects of mucous glycoprotein on nucleation time of human bile. Gastroenterology 1985;89:648-58.

5. Smith BF. Human gallbladder mucin binds biliary lipids and promotes cholesterol crystal nucleation in model bile. J Lipid Res 1987;28:1088-97.

6. Malet PF, Deng S-Q, Soloway RD. Gallbladder mucin and cholesterol and pigment gallstone formation in hamsters. Scand J Gastroenterol 1989;24:1055-60.

7. Marcus SN, Heaton KW. Deoxycholic acid and the pathogenesis of gallstones. Gut 1988;29:522-33.

8. Stolk MF, Van Erpecum KJ, Smout AJ, et al. Motor cycles with phase III in antrum are associateed with high motilin levels and prolonged gallbladder emptying. Am J Physiol 1993;264:G596-600.

9. Hardison WGM, Tomaszewski N, Grundy SM. Effect of acute alterations in small bowel transit time upon the biliary excretion rate of bile acids. Gastroenterology 1979;76:568-74.

10. Everson TG, Lawson MJ, McKinley C, Showalter R, Kern F. Gallbladder and small intestinal regulation of biliary lipid sceretion during intraduodenal infusion of standard stimuli. J Clin Invest 1983;71:596-603.

11. van der Linden W, Bergmann F. An analysis of data on human hepatic bile. Relationship between main bile components, serum cholesterol and serum triglycerides. Scand J Clin Lab Invest 1977;37:741-7.

12. Xu Q-W, Shaffer EA. Octreotide (SMS*) inhibits biliary lipid secretion and GB motility: relation to cholesterol gallstone formation in an animal model. Gastroenterology 1995;108:A116. (Abst)

13. Xu Q-W, Scott RB, Tan DTM, Shaffer EA. Slow intestinal transit: a motor disorder contributing to cholesterol gallstone formation in the ground squirrel. Hepatology 1996;23:1664-72.

14. Xu Q-W, Scott RB, Tan DTM, Shaffer EA. Erythromycin as a prokinetic agent in an animal model of cholesterol gallstone disease. Gastroenterology 1995;108:A441. (Abst)

15. Shoda J, He B-F, Tanaka N, et al. Increase of deoxycholate in supersaturated bile of patients with choelsterol gallstone disease and its correlation with de novo syntheses of cholesterol and bile acids in liver, gallbladder emptying, and small intestinal transit. Hepatology 1995;21:1291-302.

16. Hussaini SH, Murphy GM, Kennedy C, Besser GM, Wass JAH, Dowling $\mathrm{RH}$. The role of bile composition and physical chemistry in the pathogenesis of octreotide-associated gallbladder stones. Gastroenterology 1994;107:1503-13.

17. Berr F, Pratschke E, Fischer S, Paumgartner G. Disorders of bile acid metabolism in cholesterol gallstone disease. J Clin Invest 1992;90:859-68.

18. Vlahcevic ZR, Bell CC Jr, Buhac I, Farrar JT, Swell L. Diminished bile acid pool size in patients with gallstones. Gastroenterology 1970;59:165-73

19. Shaffer EA, Small DM. Biliary lipid secretion in cholesterol gallstone disease. The effect of cholecystectomy and obesity. J Clin Invest 1977;59:828-40

20. Nilsell KB, Angelin B, Leijd B, Einarsson K. Biliary lipid output and bile acid kinetics in cholesterol gallstone disease. Gastroenterology 1985;89:287-93.

21. Dowling RH, Hussaini SH, Murphy GM, Besser GM, Wass JAH. Gallstones during octreotide therapy. Metabolism 1992;41(Suppl 2): 22-33.

22. Catnach SM, Anderson JV, Fairclough PD, et al. The effect of octreotide on gallstone prevalence and gallbladder motility in acromegaly. Gut 1993;34:270-3.

23. Redfern JS, Fortuner WJ II. Octreotide-associated biliary tract dysfunction and gallstone formation: Patho-physiology and management. Am J Gastroenterol 1995;90:1042-52.

24. Newman CB, Melmed S, Snyder PJ, et al. Safety and efficacy of long-term octreotide therapy of acromegaly: Results of a multicenter trial in 103 patients - a clinical research center study. J Clin Endocrinol Metab 1995;80:2768-75.

25. Hussaini SH, Pereira SP, Murphy GM, et al. The composition of octreotide-associated gallbladder stones: response to oral ursodeoxycholic acid. Gut 1995;36:126-32.

26. Lembcke B, Creutzfeldt W, Schlesser S, Ebert R, Shaw C, Koop I. Effect of somatostatin analogue sandostatin (SMS 201-995) on gastrointestinal, pancreatic and biliary function, and hormone release in normal men. Digestion 1987;36:108-24.

27. van Liessum PA, Hopman WP, Pieters GF. Postprandial gallbladder motility during long term treatment with the long-acting somatostatin analog SMS 201-995 in acromegaly. J Clin Endocrinol Metab 1989;69:557-62

28. Ewins DL, Javaid A, Coskeran PB, et al. Assessment of gall bladder dynamics, cholecystokinin release and the development of gallstones during octreotide therapy for acromegaly. Q J Med 1992;83:295-306.

29. Stolk MFJ, van Erpecum KJ, Koppeschaar HPF, et al. Postprandial gallbladder motility and hormone release during intermittent and continuous subcutaneous octreotide therapy in acromegaly. Gut 1993;34:808-13.

30. Hussaini SH, Pereira SP, Veysey MJ, et al. The roles of gallbladder emptying and intestinal transit in the pathogenesis of octreotide-induced gallbladder stones. Gut 1996;38:775-83.

31. Swobodnik W, Hagert N, Janowitz P, Wenk H. Diagnostic fine-needle puncture of the gallbladder with US guidance. Radiology $1991 ; 178: 755-8$

32. Hussaini SH, Kennedy C, Pereira SP, Wass JAH, Dowling RH. Ultrasound-guided percutaneous fine needle puncture of the gallbladder for studies of bile composition. Br J Radiol 1995;68:271-6.

33. Fuessl HS, Carolan G, Williams G, Bloom SR. Effect of a long-acting somatostatin analogue (SMS 201-995) on postprandial gastric emptying of 99mTc-tin colloid and mouth-to-caecum transit time in man. Digestion 1987;36:101-7.

34. O'Donnell LJD, Watson AJM, Cameron D, Farthing MJG. Effect of octreotide on mouth-to-caecum transit time in healthy subjects and in the irritable bowel syndrome. Aliment Pharmacol Ther 1990;4:177-82.

35. Moller N, Petrany G, Cassidy D, et al. Effects of the somatostatin analogue SMS 201-955 (sandostatin) on mouth-to-caecum transit time and absorption of fat and carbohydrates in normal man. Clin Sci $1988 ; 75: 345-50$

36. Deuno MI, Bai JC, Sanangelo WC, Krejs GJ. The effect of somatostatin analogue on water and electrolyte transport and transit time in human small bowel. Dig Dis Sci 1987;32:1092-6.

37. Bond JH, Levitt MD. Investigation of small bowel transit time in man utilizing pulmonary hydrogen measurements. J Lab Clin Med 1974;85:546-56

38. Howard PJ, Lazarus C, Maisey MN, Dowling RH. Interpretation of postprandial breath hydrogen execretion in relation to small bowel transit and ileo-caecal flow patterns of a radiolabelled solid meal in man. J Gastrointest Motility 1990;2:194-201.

39. Metcalf AM, Phillips SF, Zinsmeister AR, MacCarty RL, Beart RW, Wolff BG. Simplified assessment of segmental colonic transit. Gastroenterology 1987;92:40-7.

40. Morris JS, Low-Beer TS, Heaton KW. Bile salt metabolism in the colon. Scand J Gastroenterol 1973;8:425-31.

41. Yahiro K, Setoguchi T, Katsuki T. Effect of caecum and appendix on 7-alpha dehydroxylation and 7 beta-epimerization of chenodeoxycholic acid in the rabbit. J Lipid Res 1980;21:215-22.

42. MacDonald IA, Bokkenheusser VD, Winter J, et al. Degradation of steroids in the human. J Lipid Res 1983;24:675-700.

43. von der Ohe MR, Camilleri M, Thomforde GM, Klee GG. Differential regional effects of octreotide on human gastrointestinal motor function. Gut 1995;36:743-8.

44. Lémann F, Flourie B, Picon L, et al. Motor activity recorded in the unprepared colon of healthy humans. Gut 1995;37:649-53.

45. Veysey MJ, Arraton SRD, Mallet A, et al. Octreotide prolongs large bowel transit, thereby increasing the proportion of deoxycholic acid in 
bile and serum and the risk of gallstones. Gut 1996;39(Suppl 1):A9. (Abst)

46. Marcus SN, Heaton KW. Intestinal transit, deoxycholic acid and the cholesterol saturation of bile: three inter-related factors. Gut 1986;27:550-8

47. Veysey MJ, Gilani SS, Pereira SP, et al. Serum deoxycholic acid (DCA) measured by gas chromatography-mass spectrometry (GC-MS) correlates with large bowel transit time (LBTT). Clin Sci 1995;89:7P. (Abst)

48. Stellaard F, Paumgartner G, van Berge Henegouwen GP, van der Werf SDJ. Determination of deoxycholic acid pool size and input rate using $\left[24,{ }^{13} \mathrm{C}\right]$ deoxycholic acid and serum sampling. J Lipid Res $1986 ; 27: 1222-5$

49. Veysey MJ, Mallet A, Murphy GM, Dowling RH. Deoxycholic acid pool size and input rate, measured by stable isotope dilution, are increased in patients with slow transit constipation. Clin Sci. (In press)

50. Heaton KW, Emmett PM, Symes CL, Braddon FEM. An explanation for gallstones in normal-weight women: slow intestinal transit. Lancet 1993;341:8-10.

51. Hussaini SH, Pereira SP, Murphy GM, Dowling RH. Deoxycholic acid influences cholesterol solubilization and microcrystal nucleation time in gallbladder bile. Hepatology 1995;22:1735-44.

52. Hofmann AF, Grundy SM, Lachin JM, et al. Pre-treatment lipid composition in which patients with gallstones in the National Cooperative Gallstone Study. Gastroenterology 1982;83:738-52.

53. Berr F, Schrieber E, Frick U. Interrelationships of bile acid and phospholipid fatty acid species with cholesterol saturation of duodenal bile in health and gallstone disease. Hepatology 1992;16:71-81.

54. Rutgeerts P, Ghoos Y, Vantrappen J, Fevery J. Biliary lipid composition in patients with non-operated Crohn's disease. Dig Dis Sci 1986;31:27-32.

55. Alvarado D, Angelico F, Atilli AF, et al. Plasma lipid lipoproteins and biliary lipid composition in female gallstone patients. Biochim Biophys Acta 1986;45:761-8.

56. Jazrawi RP, Northfield TC. Effects of pharmacological dose cholecystokinin on bile acid kinetics and biliary cholesterol saturation in man. Gut 1986;27:355-62.

57. Carulli N, Loria P, Bertolotti C, et al. Effects of acute changes in bile acid pool composition on biliary lipid secretion. J Clin Invest 1985;74:616-24.

58. Cantafora A, DiBiase A, Alvaro D, et al. High performance liquid chromatographic analysis of molecular species of phosphatidylcholine - development of quantitative assay and its application to human bile. Clin Chim Acta 1983;134:281-95.

59. van Berge Henegouwen GP, van der Werf SDJ, Ruben AT. Fatty acid composition of phospholipids in bile in man: promoting effect of deoxycholate on arachidonate. Clin Chim Acta 1987;165:27-37.

60. Hatsushika S, Tazuma S, Kajiyama G. Nucleation time and fatty acid composition of lecithin in human gallbladder bile. Scand J Gastroenterol 1993;28:131-6.

61. Pereira SP, Hussaini SH, Cassell TB, Murphy GM, Wass JAH, Dowling RH. Octreotide increases the proportions of arachidonic acid-rich phospholipids in gallbladder bile. Gut 1993;34:S32. (Abst)

62. Pereira SP, Hussaini SH, Cassell TB, Murphy GM, Wass JAH, Dowling RH. Biliary phospholipids and mucin glycoprotein are altered in octreotide-induced gallstones. Gut 1995;36(Suppl 1): A47. (Abst)

63. Messing B, Bories C, Kunstlinger F, Bernier J-J. Does total parenteral nutrition induce gallbladder sludge formation and lithiasis? Gastroenterology 1983;84:1012-9.

64. Murray FE, Stinchcombe SJ, Hawkey CJ. Development of biliary sludge in patients on intensive care unit: results of a prospective ultrasonographic study. Gut 1992;33:1123-5.

65. Sitzmann JV, Pitt HA, Steinborn PA, Pasha ZR, Sanders RC. Cholecystokinin prevents parenteral nutrition induced biliary sludge in humans. Surg Gynecol Obstet 1990;33:4-9.

66. Hasse C, Nielke A, Nies C, Al-Bazaz B, Gotzen L, Rothmund M. Influence of ceruletid on gallbladder contraction: a possible prophylaxis of acute acalculous cholecystitis in intensive care patients. Digestion 1995;56:389-94.

67. Veysey MJ, Arraton SRD, Malcolm P, et al. Can cisapride overcome the effects of octreotide on intestinal transit, thereby reducing the proportion of deoxycholic acid in bile and serum and the risk of gallstones? Gut 1996;39(Suppl 1):A8. (Abst)

68. El Oufir L, Flourie B, Bruley des Varannes S, et al. Relations between transit time, fermentation products, and hydrogen consuming flora in healthy humans. Gut 1996;38:870-7.

69. Thomas LA, Murphy GM, Dowling RH, et al. Role of bile acid metabolising intestinal bacterial enzymes in cholesterol gallstones; in vitro methods and ex vivo results in human caecal aspirates. Clin Sci. (In press)

70. Takaoka M, Kubota Y, Fujimura K, et al. Effect of single and multiple administrations of cisapride on postprandial gallbladder emptying in healthy humans. Intern Med 1994;33:381-6.

71. Thorens J, Schnegg JF, Brignoli R, et al. Effect of cisapride on gallbladder motility after extracorporeal shock-wave lithotripsy. J Hepatol 1995;22:333-7.

72. Veysey MJ, Malcolm P, Jenkins P, et al. Can cisapride overcome the effects of octreotide (OT) on gallbladder emptying. Gut 1996;39(Suppl 3): A103-4. (Abst)

73. Pomare EW, Heaton KW, Low-Beer TS, Espiner HJ. The effect of wheat bran upon bile salt metabolism and upon the lipid composition of bile in gallstone patients. Am J Dig Dis 1976;21:521-6.

74. Hood KA, Gleeson D, Ruppin DC, Dowling RH and the BritishBelgian Gallstone Study Group. Gallstone recurrence and its prevention: The British/Belgian gallstone study group's post-dissolution trial. Gut 1993;34:1277-88.

75. Portincasa P, Di Ciaula A, Palmieri VO, Baldassare G, Palasciano G. Enhancement of gallbladder emptying in gallstone patients after oral cholestyramine. Am J Gastroenterol 1994;89:909-14.

76. O'Donnell LJD, Wilson P, Guest P, et al. Indomethacin and post-prandial gallbladder emptying. Lancet 1992;339:269-71.

77. Marzio L, Di Gammarco AM, Capone F, et al. Effect of cisapride on human fasting gallbladder volume: A real-time ultrasonographic study. Eur J Clin Pharmacol 1986;29:631-3.

78. Wiseman LR, Faulds D. Cisapride. An updated review of its pharmacology and therapeutic efficacy as a prokinetic agent in gastrointestinal motility disorders. Drugs 1994;47:116-52.

79. Catnach SM, Fairclough PD, Trembath RC, et al. Effect of oral erythromycin on gallbladder motility in normal subjects and subjects with gallstones. Gastroenterology 1992;102:2071-6.

80. Weber FH, Richards RD, McCallum RW. Erythromycin: A motilin agonist and gastrointestinal prokinetic agent. Am J Gastroenterol 1993;88:485-90

81. Thornton JR, Heaton KW. Do colonic bacteria contribute to cholesterol gall stone formation? Effects of lactulose on bile. BMJ 1981;282:1018-20. 


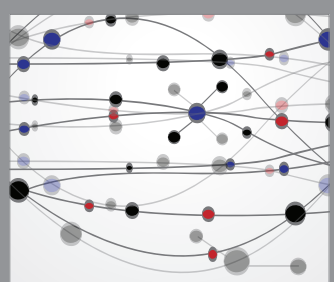

The Scientific World Journal
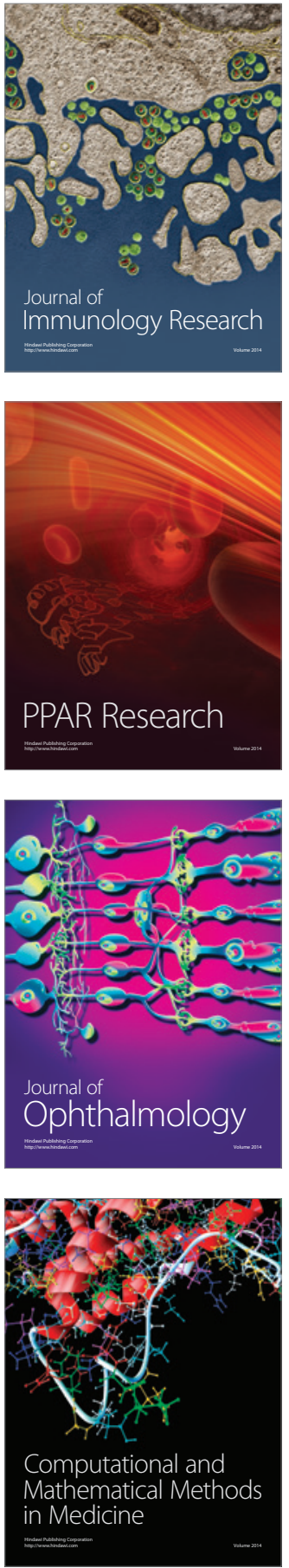

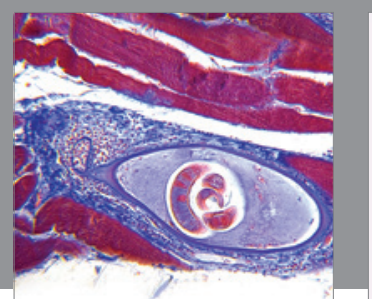

Gastroenterology Research and Practice

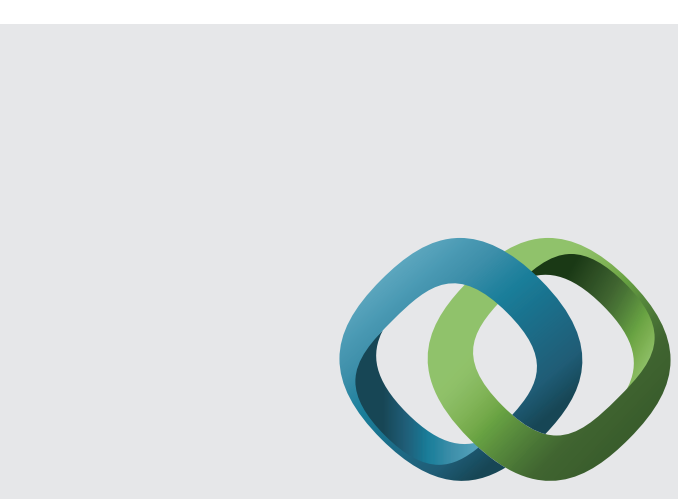

\section{Hindawi}

Submit your manuscripts at

http://www.hindawi.com
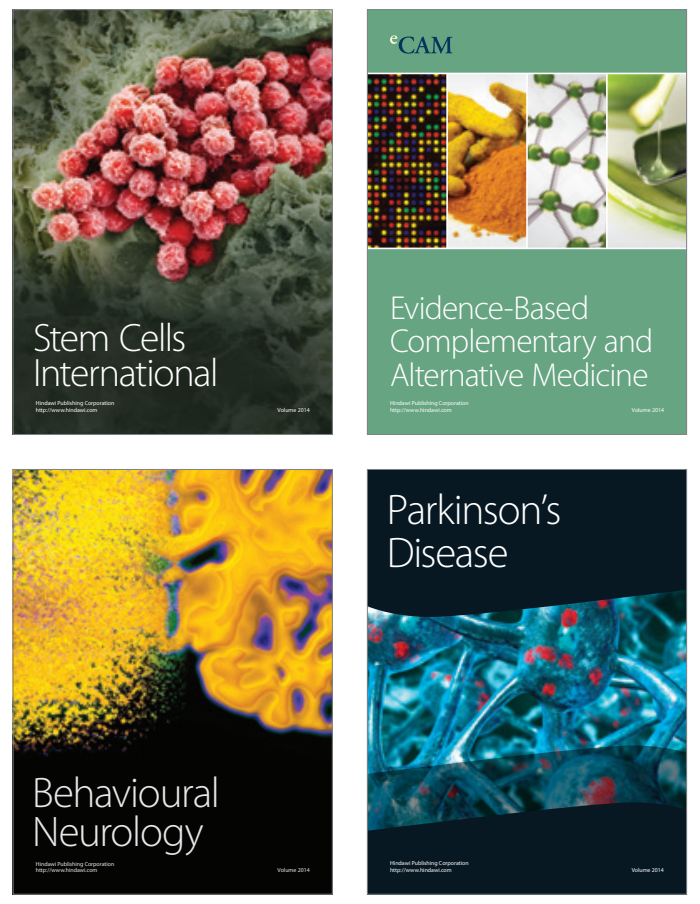
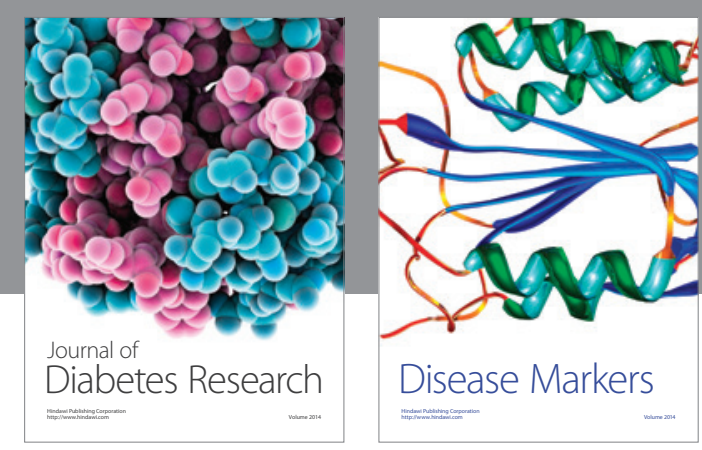

Disease Markers
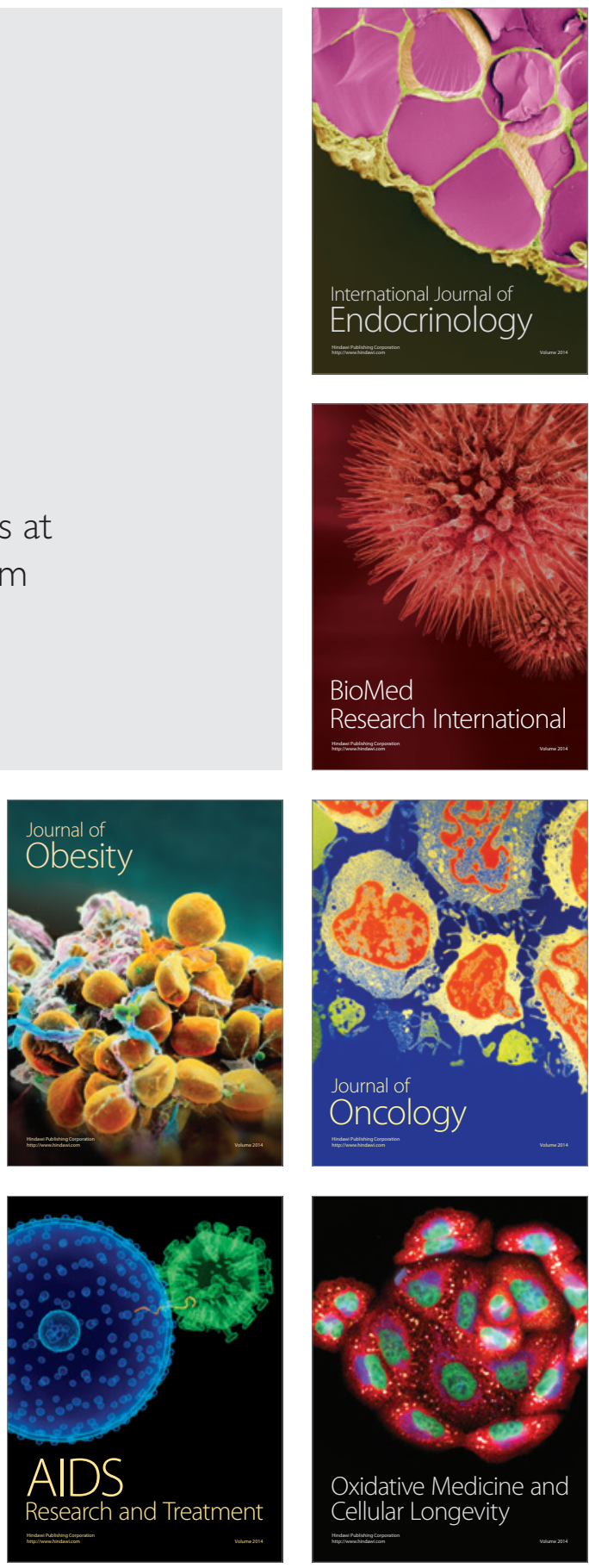